\title{
ATUAÇÃO DA ENFERMEIRA EM COMITÊ TRANSFUSIONAL
}

Leomar Albini ${ }^{1}$, Liliana Maria Labronici² ${ }^{2}$, Maria Ribeiro Lacerda ${ }^{3}$

RESUMO: Este relato tem como objetivo apresentar a experiência da enfermeira em um Comitê Transfusional em instituição pública de ensino. Toda transfusão sanguínea traz riscos ao receptor. A formação de Comitê Transfusional é fundamental e, integrante neste processo, se destaca a atuação da enfermeira no planejamento, implementação e avaliação de ações direcionadas à terapia transfusional segura. O resultado da atuação desta profissional está na construção de um comitê com bases sólidas, reconhecido internamente, servindo de modelo para outras instituições e, principalmente, na diminuição das intercorrências transfusionais.

PALAVRAS-CHAVE: Enfermagem; Sangue; Sistema de Vigilância Sanitária.

\section{ACTION OF THE NURSE IN A TRANSFUSION COMMITTEE}

\begin{abstract}
This report aims to present the experience of a nurse in a Transfusion Committee at public schools. Whole blood transfusion carries risks to the receiver. The formation of a Transfusion Committee is fundamental and it is included in this process. The role of the nurse in planning, implementation and evaluation of actions regarding a safe transfusion therapy is highlighted.. The result of the nurse's performance is the construction of a committee with a solid foundation, which is internally known and a model for other institutions and, especially, by the reduction of transfusion complications.
\end{abstract}

KEYWORDS: Nursing; Blood; Health Surveillance System.

\section{ACTUACIÓN DE LA ENFERMERA EN COMITÉ DE TRANSFUSIÓN}

RESUMEN: Este relato tiene como objetivo presentar la experiencia de la enfermera en un Comité de Transfusión en institución pública de enseñanza. Toda transfusión de sangre trae riesgos al receptor. La formación de Comité de Transfusión es fundamental y, integrante en este proceso, se destaca la actuación de la enfermera en planeamiento, implementación y evaluación de acciones dirigidas a la terapia de transfusión segura. El resultado de la actuación de esta profesional está en la construcción de un comité con bases sólidas, reconocido internamente, siendo modelo para otras instituciones y, principalmente, en la disminuición de las ocurrencias en transfusión.

PALABRAS CLAVE: Enfermería; Sangre; Sistema de Vigilancia Sanitaria.

${ }^{1}$ Enfermeira. Mestre em Enfermagem. Doutoranda do Programa de Pós-Graduação em Enfermagem da Universidade Federal do Paraná-UFPR. Enfermeira do Comitê Transfusional do Hospital de Clínicas da UFPR. Membro do Núcleo de Estudos Pesquisa e Extensão do Cuidado Humano em Enfermagem-NEPECHE-UFPR.

${ }^{2}$ Enfermeira Doutora em Enfermagem. Professor Adjunto do Departamento de Enfermagem da UFPR. Membro do Grupo de Estudos Multidiciplinar em Saúde do Adulto-GEMSA.

${ }^{3}$ Enfermeira. Doutora em Enfermagem. Professor Adjunto do Departamento de Enfermagem da UFPR. Coordenadora do Programa de Pós-Graduação em Enfermagem da UFPR. Membro do NEPECHE-UFPR.

\author{
Autor correspondente: \\ Leomar Albini \\ Universidade Federal do Paraná \\ Rua Heitor Baggio Vidal, 1952 - 82820-120 - Curitiba-PR, Brasil \\ E-mail: albinileomar@ig.com.br
}

Recebido: 15/09/09 Aprovado: 05/08/10 


\section{INTRODUÇÃO}

A transfusão de sangue é parte importante da assistência à saúde contemporânea. Contudo, paralelo aos seus benefícios, caminham os riscos de complicações agudas e tardias, relacionadas a diferentes causas, como erros de identificação de pacientes e amostras, e uso de produtos inadequados.

Muitos países estabeleceram serviços nacionais de transfusão sanguínea de acordo com as normas e recomendações da Organização Mundial da Saúde (OMS), a fim de estabelecer políticas nacionais de educação e treinamento sobre o uso clínico do sangue e seus derivados. Neste sentido, a constituição de um Comitê Transfusional (CT) vem contribuir para a garantia da segurança transfusional, conforme resolução RDC n. 153 de 14 de junho de 2004 da Agência Nacional de Vigilância Sanitáriaa ${ }^{(1)}$, publicada em Diário Oficial da União, aprovando o Regulamento Técnico dos Serviços de Hemoterapia.

Seguindo estas recomendações, em 2004, houve a criação do CT de natureza técnico-científica de caráter permanente na instituição pública referente a este relato, com a finalidade de monitorar a prática hemoterápica local, contribuindo, assim, tanto para a gestão e utilização racional do sangue como para a redução de incidentes na área.

Esse Comitê conta com profissionais de diferentes especialidades da área de saúde e que atuam na instituição. Nesta realidade, destaca-se a atuação da enfermeira. Esta profissional tem sua formação direcionada ao gerenciamento do cuidado, à educação, pesquisa e trabalho em equipe, componentes fundamentais para que um comitê apresente resultados positivos $^{(2)}$. Diante do exposto, este relato tem como objetivo apresentar a vivência profissional da enfermeira em um CT.

\section{TRANSFUSÃO SANGUÍNEA}

A temática relacionada ao sangue sempre despertou o interesse da humanidade ao longo da história, ocupando um espaço entre o científico e o místico. Na Grécia antiga, os gladiadores romanos ingeriam sangue, acreditando que a vida, a força e a coragem estavam ligadas a este componente. No antigo Egito, era comum a utilização de sangue de animais sacrificados para o aumento da fertilidade do solo. Galeno, por volta de 170 d.C., inseriu a prática de retirada de sangue humano para tratamentos de saúde.
Existem relatos imprecisos de que o uso terapêutico do sangue em seres humanos data de 1492, quando o Papa Inocêncio VIII supostamente recebeu uma transfusão $0^{(3)}$.

O grande avanço nesta área ocorreu em 1569, quando Andréa Cisalpino descobriu a circulação sanguínea, descrita em 1627 por Willian Harvey, fato considerado como a base verdadeiramente científica da transfusão( ${ }^{(4)}$. A primeira transfusão de sangue de um animal para ser humano foi relatada em 1667; na sequência, passou-se para o sistema braço a braço, ou seja, de ser humano para outro. Devido aos insucessos, esta prática ficou proibida durante 150 anos na Europa. Em 1900, Landesteiner descobriu que existiam diferentes tipos sanguíneos entre as pessoas, denominando-os de $\mathrm{A}, \mathrm{B}, \mathrm{AB}$ e $\mathrm{O}^{(4)}$.

As primeiras referências citadas na literatura sobre indicações transfusionais aparecem por volta de 1930. Antes, em 1926, surgiu em Moscou o primeiro Centro de Hematologia e Transfusão de sangue, apesar do Fator RH ter sido descoberto somente em $1942^{(5)}$.

A terapia transfusional se apresenta como uma intervenção complexa, de alto custo e sujeita a riscos na sua execução. Destaca-se o papel da Enfermagem, pois são seus profissionais que se mantêm próximo ao paciente durante a transfusão sanguínea ${ }^{(6)}$.

\section{EXPERIÊNCIA DO ENFERMEIRO NO COMITÊ TRANSFUSIONAL}

Os primeiros Comitês de Transfusão Sanguínea Hospitalares surgiram na década de 80 do século XX, com a finalidade de garantir a correta utilização de sangue e hemoderivados. Na década de 1990, houve um amplo consenso das organizações internacionais, dentre elas a OMS e o Conselho da Europa, quanto à necessidade de criação destas estruturas nos hospitais ${ }^{(5)}$.

Neste sentido, para o início dos trabalhos do CT local, houve a inserção de uma enfermeira com experiência em hematologia e educação permanente. Coube a esta profissional a proposta de composição e planejamento das atividades iniciais do CT, fundamentais para a construção de uma base sólida de atuação diante de uma nova perspectiva profissional. As dificuldades foram sentidas logo no início, pois sendo algo recente, poucas instituições nacionais possuíam um comitê organizado e atuante. Especificamente para a Enfermagem, trabalhos que pudessem direcionar o início das atividades não foram encontrados.

Desta feita, pensando na construção desse 
novo fazer, as primeiras ações ocorreram por meio de reuniões de planejamento e organização, em parceria com a direção da instituição. Nesta fase, destaca-se a inclusão de enfermeiras como membros efetivos, representes das unidades de maior consumo de hemocomponentes.

No seguimento, houve a realização de um diagnóstico situacional, identificando as necessidades e interesses da equipe de enfermagem no que se refere aos cuidados do cliente submetido à terapia transfusional. Verificou-se que, mesmo nas unidades em que este procedimento era realizado com frequência, a equipe de enfermagem possuía dúvidas sobre questões amplas, como transfusão incompatível, sistema $\mathrm{ABO}$, e itens mais específicos, como coleta de amostra de sangue, armazenamento, tempo de infusão de hemocomponentes, dentre outros. Informações importantes também foram obtidas a partir da revisão de prontuários e dos registros de enfermagem.

Atualmente, a verificação dos prontuários é uma das atividades que traz resultados mais eficazes na qualidade das transfusões. Rotineiramente, uma vez por mês, as enfermeiras do CT realizam a análise de prontuários das unidades de maior consumo de hemocomponentes. Esta etapa é feita segundo roteiro elaborado em parceria com a Comissão de Acreditação da instituição. Os itens avaliados correspondem à prescrição médica, requisição de transfusão, ato transfusional e reação transfusional, seguindo as determinações da legislação específica da Agência Nacional de Vigilância Sanitária (ANVISA) e dos Procedimentos Operacionais-Padrão do Comitê Transfusional (POPs) do CT da instituição.

As não-conformidades identificadas são relatadas ao enfermeiro responsável pela unidade, a fim de que este possa orientar sua equipe de modo a cumprir as normas referentes aos cuidados em transfusão sanguínea. Paralelamente a esta atividade de educação, a realização de palestras é uma atividade contínua exercida pelas enfermeiras do CT. Os temas são direcionados ao cuidado em transfusão em pacientes críticos, transfusão maciça, transfusão em pediatria, em idosos, dentre outros.

Além disso, em relação ao programa de educação permanente, já no primeiro ano de funcionamento, ocorreu um ciclo de palestras com o tema: "Orientações em Transfusão Sanguínea", direcionado a enfermeiros, técnicos e auxiliares de enfermagem, com a participação de hemoterapeutas, farmacêuticos e enfermeiras. O conteúdo do evento procurou abran- ger desde a dispensação do hemocomponente pelo banco de sangue, até os cuidados de enfermagem nas diferentes etapas da transfusão sanguínea, finalizando com os cuidados em reações transfusionais.

Nesta caminhada, destaca-se que o primeiro encontro consistiu em uma oficina de trabalho direcionada aos enfermeiros membros do $\mathrm{CT}$, tendo como propósito a apresentação e discussão da proposta de trabalho deste grupo, as ações direcionadas à Enfermagem e a análise e discussão da Resolução n. 153 da ANVISA. Na mesma linha de importância, foram realizados fóruns direcionados à comunidade interna e externa, tendo como destaque o fórum que teve como tema central: "Transfusão sanguínea em Testemunhas de Jeová".

Além destas estas práticas educativas, foram elaborados materiais de apoio para os profissionais de saúde da instituição, como folhetos com as orientações sobre transfusões sanguíneas, manuais e protocolos específicos, que são atualizados anualmente. Todo este material de apoio se encontra disponível on line na página da instituição.

Dentre todas as realizações da enfermeira no CT, uma das mais importantes está direcionada à educação em serviço relacionada com a prevenção e resolução de problemas específicos ocorridos nas unidades.

Estas foram algumas atividades realizadas, direta ou indiretamente, pela enfermeira do CT, acreditando-se que importante é estabelecer o elo entre aqueles que executam os procedimentos durante a transfusão sanguínea e o CT; deste modo, o conhecimento pode ser compartilhado e as atividades constantemente reavaliadas.

\section{CONSIDERAÇÕES FINAIS}

Atualmente, resultados concretos da atuação do CT podem ser observados pela diminuição de intercorrências transfusionais na instituição, pois os índices se apresentam inferiores aos que a literatura preconiza. O reflexo da atuação da enfermeira neste cenário é notado, tanto na comunidade interna como na externa, por meio de convites recebidos para ministrar aulas e auxiliar na organização de comitês em outras instituições. Além disso, a solicitação para participação em reuniões nas unidades e serviços mostra a mudança de comportamento da equipe de enfermagem, com a preocupação na condução do cuidado aos usuários submetidos à terapia transfusional. 
A organização de um CT é um longo caminho a percorrer, permeado de dificuldades e êxitos, que impulsionam e motivam. As atividades realizadas são continuamente avaliadas e servem de base a novos planejamentos. Assim, o que já foi construído pode ser sedimentado e novos desafios propostos. Em determinados serviços, é necessário retomar várias vezes as orientações básicas, pois a resistência a mudanças é uma constante, o que exige persistência e comprometimento.

A integração deste Comitê com acadêmicos da área de saúde está sendo construída. Acadêmicos de diversas instituições visitam o Serviço de Hemoterapia e conhecem o funcionamento do CT. Desta forma, as ações deste Comitê estão sendo constantemente ampliadas.

\section{REFERÊNCIAS}

1. Agência Nacional de Vigilância Sanitária. Resolução n. 153 , de 14 de junho de 2004. Dispõe sobre procedimentos hemoterápicos e uso humano de sangue e seus componentes. Agência Nacional de Vigilância Sanitária, 2004.

2. Amestoy SC, Cestari ME, Thofehrn MB, Milbrath VM, Porto AR. Enfermeiras refletindo sobre seu processo de trabalho. Cogitare Enferm. 2010;15(1):158-63.

3. Pacheco FC. Crise e risco na história da transfusão de sangue. Rev Med Transfusioanl. ABO. 2003;(16):1223.

4. Junqueira LC, Carneiro J. Histologia básica. $8^{\mathrm{a}}$ ed. Rio de Janeiro: Guanabara Koogan; 1995.

5. Petz LD, Kleinman S, Swisher SN, Spence RK, Strauss RG. Clinical practice of transfusion medicine, 3rd ed. New York: Churchill Livingsstone; 1996.

6. Albini L, Almeida PTR. Terapia de suporte. In: Ortega ETM, Kojo TK, Lima DH, Veran MP, Neves MI. Compêndio de enfermagem em transplante de células tronco hematopoiéticas: rotinas e procedimentos em cuidados essenciais e em complicações. Curitiba: Maio; 2004. p. 169-72. 